\title{
Erythrocyte Alloimmunization in Children with Sickle Cell Disease
}

\section{Daniela de Oliveira Werneck Rodrigues ${ }^{1,2,4^{*}}$ (D), Lysla Cardoso Sudário ${ }^{3}$ (D) Olivia Franco dos Santos (iD) Leonardo de Angelli Benedito Cardoso ${ }^{1}$ (D) and Luiz Claudio Ribeiro ${ }^{1}$ (D)}

${ }^{1}$ Universidade Federal de Juiz de Fora, Juiz de Fora, Brazil

${ }^{2}$ Fundação Hemominas, Brazil

${ }^{3}$ Hospital Maternidade Therezinha de Jesus, Juiz de Fora, Brazil

${ }^{4}$ Researcher at NHLBT-NIH, USA

*Corresponding author: Daniela de Oliveira Werneck Rodrigues, Fundação Hemominas, Juiz de Fora, MG, Brazil; Universidade Federal de Juiz de Fora (UFJF), Rua Dr. Antônio Carlos, 430/1400, Juiz de Fora, MG, CEP 36010-560, Brazil, Tel: +553299796484; +553232573126, E-mail: daniela.werneck@hemominas.mg.gov.br

\begin{abstract}
Background: Alloimmunization is an immune response against red blood cell (RBC) antigens due to sensitization during $\mathrm{RBC}$ transfusion. RBC alloimmunization is more common in sickle cell disease (SCD) with prevalence between 18 and $47 \%$.
\end{abstract}

Objectives: To determine the prevalence and rate per unit exposure of alloimmunization in children with SCD and to identify the most frequent RBC antibodies.

Methods: Retrospective chart review of a cohort of 120 children treated at Fundação Hemominas born between 1998 and 2007 and diagnosed with SCD through neonatal screening. The statistical analysis was made with the usage of Mann-Whitney's U test, Student's T-test and Chi-Square test.

Results and conclusion: Among the 72 children, who had been transfused, $55.6 \%$ were male and $76.4 \%$ had SS/SB0. The average age was 11.5 -years-old and the prevalence of alloimmunization was $11.1 \%$ with a mean age of 5.25 years at diagnosis. The risk of alloimmunization in children who had $\leq 10$ transfusions was $70 \%$ lower than those with $>10$ transfusions (RR $=0.300$-Confidence Interval 95\%: 0.0781.151). Alloimmunization rate per 100 units of $R B C$ was 0.41 . The association of age, transfusion and alloimmunization using the Mann-Whitney's $U$ test was not statistically significant for each interval studied. The presence of $9.8 \%$ antibodies belonging to the Rh system in the alloimmunized group was observed. It is well known that the presence of alloantibodies complicates the treatment of serious conditions such as acute chest syndrome and stroke. Therefore, measures to prevent alloimmunization should be adopted by the transfusion services in order to reduce this complication.

\section{Keywords}

Sickle cell disease, Blood transfusion, Alloantibodies, Transfusion reaction, Neonatal screening

\section{Introduction}

Sickle cell disease (SCD) comprises a group of hematological alterations caused by the presence of hemoglobin S ( $\mathrm{Hb} \mathrm{S}$ ), either homozygous SS or in combination with other variants of hemoglobins $(\mathrm{Hb})$ - such as $\mathrm{HbC}$ and other of hemoglobinopathies like Beta Thalassemia $[1,2]$. It is estimated that about 3,000 children are born each year with SCD in Brazil [3].

Transfusion of red blood cells (RBC) has a crucial role in the therapeutic arsenal of $S C D$, resulting in reduced morbidity and mortality [4-9]. One complication of RBC transfusion therapy is alloimmunization, an immune response against blood group antigens triggered by a genetic disparity between donor and recipient $[10,11]$. According to Schonewille, et al. [7], the risk of alloimmunization depends on the exposure of the recipient to a foreign antigen, the immunogenicity of this antigen and the number and frequency of transfusions. Genetic factors controlling inflammatory responses may activate the innate immune system and convert an inert or even a tolerogenic event into an immunogenic one [9]. Alloimmunization occurs more frequently in SCD when

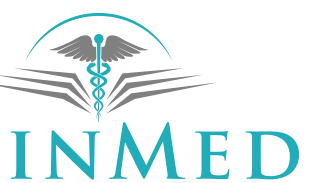

INTERNATIONAL LIBRARY

Citation: Rodrigues DOW, Sudário LC, Santos OF, Cardoso LAB, Ribeiro LC (2020) Erythrocyte Alloimmunization in Children with Sickle Cell Disease. Int J Blood Res Disord 7:059. doi.org/10.23937/24695696/1410059

Accepted: November 14, 2020: Published: November 16, 2020

Copyright: (c) 2020 Rodrigues DOW, et al. This is an open-access article distributed under the terms of the Creative Commons Attribution License, which permits unrestricted use, distribution, and reproduction in any medium, provided the original author and source are credited. 
compared to other diseases such as cancer and other hemoglobinopathies, with alloimmunization rates between $18-47 \%$ for SCD $[7,9,10]$. The main alloantibodies found are directed against antigens of the Rhesus system, Kell, Duffy, Kidd, Lewis and MNS, and is primarily due to antigenic differences between blood recipients and donors [10,12-17].

The objectives of this study were to determine the prevalence and alloimmunization rate among transfused children with SCD treated at Hemominas Juiz de Fora (JFO), as well as to identify the most common antibodies in alloimmunization and risk factors for alloimmunization in this population.

\section{Materials and Methods}

\section{Population}

A retrospective cohort study was conducted to evaluate the prevalence of alloimmunization among 120 children born between 1998-2007 diagnosed with SCD through the Programa Estadual de Triagem Neonatal de Minas Gerais (PETN-MG), treated at Hemominas Juiz de Fora (JFO). Standardized case report forms were used to abstract data from medical records. All patients included in the cohort were followed up for at least 7 years.

The researchers decided to include all the children in the study and not to do the sample calculation, considering the reduced number of patients with alloimmunization. The children were stratified into transfused and non-transfused groups. The 72 children transfused were analyzed for this study (Figure 1). Ten children who died (9 from sepsis and 1 from splenic sequestration) were not included.

\section{Variables studied}

The data collection period started in August 2013 and was completed in December 2014. Variables abstracted from medical record included: Sex, age, type of hemoglobinopathy, RBC phenotype for $A B O, R h(C$, $c, E, e, C w, D)$, Kell $(K, k)$, Duffy $\left(F y^{a}, F y^{b}\right)$, Kidd $\left(J k^{a}, J k^{b}\right)$, Lewis $\left(L^{a}{ }^{a}, L^{b}\right), M N S s$, Indirect Antiglobulin Test (IAT RBC Antibody Screen), date of diagnosis of positive IAT, number of transfusions, location of transfusions, number of transfusions by age, number of previous units transfused to the positive IAT, identified alloantibodies and chronic transfusion treatment.

Children were stratified into patients transfused only at JFO, transfused at JFO and another facility or transfused at another facility only, as well as the type of blood leukoreduced. For the analysis, the number of transfusions was categorized into 2 groups: (1) Up to ten and (2) Above 10 transfusions in the observation period. The outcome variable for all analyses was development of RBC antibody.

\section{Laboratory tests}

Testing for abnormal hemoglobin was performed by high performance liquid chromatography (HPLC) and isoeletric focusing electrophoresis (IEF) on agarose gel with blood obtained by heel stick and applied to filter paper.

Confirmatory diagnosis of SCD and their respective classification in $\mathrm{SS}, \mathrm{SC}, \mathrm{S}$ beta-thalassemia $\left(\mathrm{S} \beta^{+}, \mathrm{S} \beta^{0}\right)$ was performed by hemoglobin electrophoresis at alkaline and acid $\mathrm{pH}$ at 6 and 12-months-old; determination of A2 Hemoglobin levels by chromatography and Fetal Hemoglobin by radial immunodiffusion.

The determination of the RBC phenotype and screening for RBC antibodies relied on the collection of $5 \mathrm{ml}$ of whole blood, as defined in the Sickle Cell Disease Guideline - Basic Flue treatment - available in http:// www.saude.gov.br/bvs. All samples with positive IAT - antibody screening had antibody identification with erythrocyte antigens panel. The samples were tested for the direct and reverse blood typing using the tube technique [18]. The Direct and Indirect Anti-globin Test, erythrocyte panel, autoantibody screen and phenotyping of other blood systems were performed by gel centrifugation technique using specific gel-test card (DiaMed $^{\circledR}$ Latin America SA, Brazil).

Erythrocyte phenotyping for the Rh (D, C, E, e), Kell (K, k), Duffy (Fya, Fyb) and Kidd (Jka, Jkb) systems antigens was performed by column-gel-test (Diamed AG, Morat, Switzerland) with polyclonal or monoclonal antibodies. The research and identification of irregular antibodies was performed using a gel-test hemaglutination method using phenotyped red cells (DiaMed ${ }^{\circledR} A G$, Cressier sur Morat ${ }^{\circledR}$, Switzerland). Whenever necessary, direct polymorphic or mono specific human antiglobulin tests, antibody adsorption and elution tests, and indirect human antiglobulin tests with selected phenotype red blood cells were also performed.

The IAT - antibody screening is annual and recommended three months after each transfusion. In the ideal situation, RBC antibody tests after transfusion should be performed twice, the first time shortly after transfusion, to detect boosting of existing antibodies or fast appearing new antibodies (i.e., anti-Jka and anti-E), and a second time after a longer period of time, to detect slower developed antibody specificities. Our study design does not allow us to be more specific on the time points.

\section{Statistical analysis}

The statistical analysis of the association was performed using the Mann-Whitney $U$ test for non-parametric data, Student's T-Test for parametric data and Chi-square test for proportions using SPSS Inc., Chicago14 ${ }^{\circledR}$ for all analyses. The statistical analysis was univariate due to the reduced number of cases with positive irregular antibody. A $p$ value of $<0.05$ was considered statistically significant. 


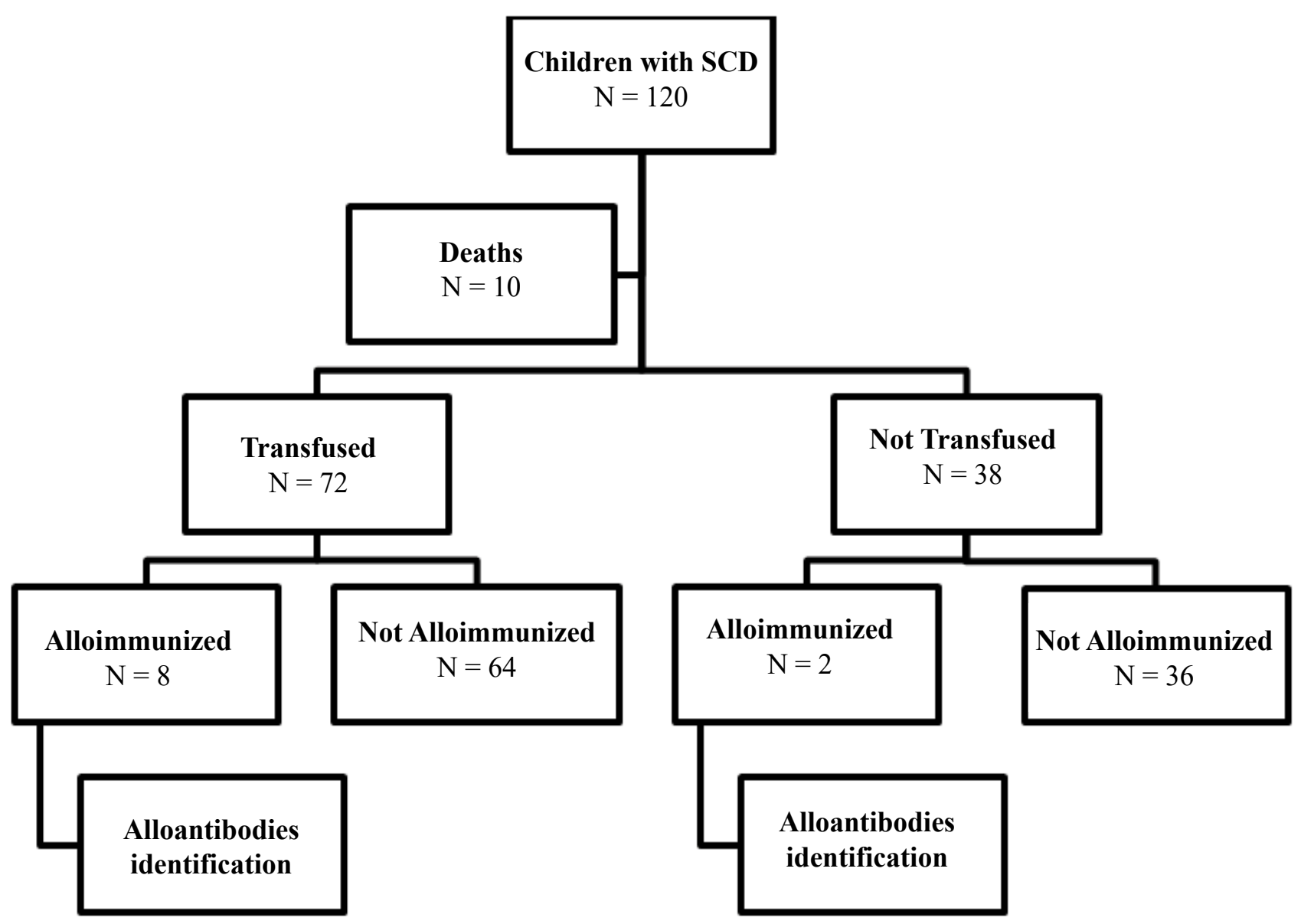

Figure 1: Stratification of the research subjects.

\section{GENOTYPE DISTRIBUTION}

\section{$\square S C A=S C \square S B-T h a l \square S B O=S B+$}

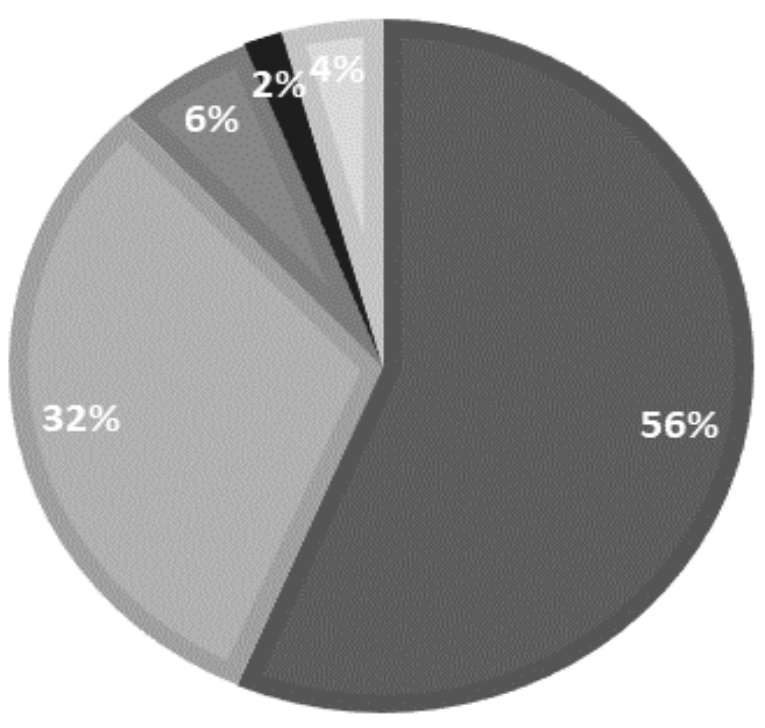

Figure 2: SCD genotype distribution.

\section{Ethical considerations}

This study project was submitted to the Plataforma Brasil and approved by the Research Ethics Committee of Fundação Hemominas (No. 716.359). It is also in accordance with the provisions of Resolution No. 466/12 of the National Health Council, Declaration of Helsinki (2008) and the Code of Medical Ethics 1988 (Article 122130).

\section{Results}

Of the 120 children born between the years 19982007 with SCD diagnosis through the PETN-MG and treated at Hemominas 110 were evaluated for this study and 72 were transfused (Figure 1). Among these 110 children studied, $52.7 \%$ were male.

The average age at the end of follow-up was $11.2 \pm$ 2.84 years-old (range 6-16). The majority of the patients were SS and the distribution of the genotypes is shown in the graph below (Figure 2).

There were 10 children (9.1\%) with anti-erythrocyte antibodies, 8 children had received transfusion and 2 had naturally alloimmunized without previous history of transfusion or pregnancy. As for children with positive IAT - antibody screening, 6 were male, 9 children had SS and 1 a child was of the SC genotype.

The analyzed group was composed of 72 transfused children, $55.6 \%$ of which were male. The average age at the end of the extraction of the data was 11.5 years (range 7-16 and standard deviation 2.74). Regarding the diagnosis, $76.4 \%$ had SS, $15.3 \% \mathrm{SC}, 5.6 \% \mathrm{~S} \beta^{+}$and $2.8 \% \mathrm{~S} \beta^{0}$. 
As for the blood classification in the ABO/Rh system between children with SS, there was a higher prevalence of the O/Positive (45.5\%), followed by group A/ Positive (23.6\%). Similar distribution was shown in the transfused group. In SCD SC type and S/ $\mathrm{b}^{+}$group, O/Positive was also predominant $(54.5 \%$ and $75 \%$, respectively).

The study of irregular antibodies was positive in 8 transfused individuals with prevalence of $11.1 \%$. All alloimmunized children had SS, three belonging to blood group O/Positive, two $\mathrm{AB} /$ Positive, two $\mathrm{B} /$ Positive and two A/Positive. The mean age at the time of positive IAT - antibody screening was 5.25-years-old (range 1-8 and standard deviation 2.37).

Among the 48 children who received between 1 to 10 transfusions, 3 were RBC antibody positive (6.3\%), and among the 24 who received more than 10 transfusions, 5 had RBC antibodies (20.8\%). The relative risk $(R R=0.300-95 \%$ Confidence Interval: 0.078-1.151) indicates that the risk of having positive IAT - antibody screening among subjects who received up to 10 transfusions is $70 \%$ lower than those who received higher amounts, though this difference was not statistically significant $(p=0.063)$.

Regarding the type of transfused blood component, $59.3 \%$ of children received $\mathrm{RBC}, 11 \%$ received pheno- typed leukoreduced $\mathrm{RBC}$ and $29.7 \%$ received both $\mathrm{RBC}$ and phenotyped leuko reduced RBC. The analysis of the positive IAT - antibody screening, type of RBC infused and the local of transfusion showed that despite the use of phenotyped Trocar para and leukoreduced RBC there was development of alloantibodies in this study $(p=0.00)$.

Children with SCD were studied in age ranges with the extraction of the number of transfusions in each interval. In the group with antibodies, the total number of transfusions in the 0-4 years-old subgroup was 5 RBC units (range 0-22 and standard deviation 7.8). The children between 5 and 10 years received an average of 11.6 units (range 1-35 and standard deviation of 12.7). From the age of 11 , children with SCD had an average of 2.6 units transfused RBC (minimum of 0 , maximum of 17 and a standard deviation of 5.9). Statistical analysis was performed for comparison with non-transfused group alloimmunized, using the Mann-Whitney test and there was no statistical significance $(p=0.420, p=0.064$ and $p=0.825$ for each age interval).

As for the amount of transfusions, the positive IAT - antibody screening group has average 19.25, median 11.5 , with minimum number of two and maximum of 67 units. Negative IAT - antibody screening group has average 11.8, median 5.0, minimum one unit, and max-

Table 1: Demographic data of Alloimmunized vs. Not-alloimmunized.

\begin{tabular}{|c|c|c|c|}
\hline Demographic data & Alloimmunized $(n=8)$ & Not-Alloimmunized $(n=64)$ & P value \\
\hline Age (years old) & $12.25( \pm 2.5)$ & $11.48( \pm 2.8)$ & $0.460^{*}$ \\
\hline Gender & & & $0.675^{* * *}$ \\
\hline Male & $5(62.5 \%)$ & $35(54.7 \%)$ & \\
\hline Female & $3(37.5 \%)$ & $29(47.3 \%)$ & \\
\hline Diagnose & & & $0.095^{* * *}$ \\
\hline SCA & $8(100 \%)$ & $47(73.4 \%)$ & \\
\hline SCD & 0 & $17(26.6 \%)$ & \\
\hline Type of Blood Component & & & $0.464^{* *}$ \\
\hline RBC (NON Phenotyped leukoreduced) & $4(50 \%)$ & $38(59.3 \%)$ & \\
\hline Phenotyped leukoreduced RBC & $2(25 \%)$ & $7(11 \%)$ & \\
\hline RBC and Phenotyped leukoreduced RBC & $2(25 \%)$ & $19(29.7 \%)$ & \\
\hline \multicolumn{4}{|l|}{ Total number of transfusions } \\
\hline Total & $19.25( \pm 21.9)$ & $11.8( \pm 20.2)$ & $0.085^{\star \star}$ \\
\hline \multicolumn{4}{|l|}{ Total number of transfusions within Age groups } \\
\hline $0-4$ years-old & $5.0( \pm 7.8)$ & $2.2( \pm 4.0)$ & $0.420^{* *}$ \\
\hline $5-10$ years-old & $11.6( \pm 12.7)$ & $6.3( \pm 10.8)$ & $0.064^{* *}$ \\
\hline Over 10-years-old & $2.6( \pm 5.9)$ & $3.3( \pm 13.2)$ & $0.825^{\star \star}$ \\
\hline Total number of transfusions & & & $0.063^{* * *}$ \\
\hline$\leq 10$ transfusions & $3(6.3 \%)$ & $45(93.8 \%)$ & \\
\hline$>10$ transfusions & $5(20.8 \%)$ & $19(79.2 \%)$ & \\
\hline $\begin{array}{l}\text { RBC units transfused previous positive IAT - Antibody } \\
\text { screening }\end{array}$ & $8.0( \pm 12.9)$ & - & \\
\hline Chronic Transfusion Therapy & $2(22.2 \%)$ & $7(77.8 \%)$ & $0.257^{*}$ \\
\hline
\end{tabular}

"Student's T-test "*Mann-Whitney's U test and "***Pearson's Chi Square Test 
imum 133 units. The prevalence of alloimmunization in multiple transfusions (children who received more than 10 transfusions) was $20.8 \%$. Table 1 shows the results found in the study group.

There were 18 irregular antibodies in $11.1 \%$ of children. Of total antibodies, seven belong to the Rh system (4 Anti-E and Anti-C 3); four to the Kidd system (3 Anti-Jka and Jkb Anti-1); three to the MNS system (2 and -M 1 Anti Anti -S); two to the Kell system (Anti-Kell) and one to the Duffy system (anti-Fyb). There was expression of cold antibody without specificity in one child and was still identified cold antibody in low titer in one case.

The chronic transfusion therapy (CTT) was used in 9 children ( 7 boys), who received 484 RBC units, averaging 53.8 transfusions (median 50.0). Among these patients, six children due to stroke and 3 patients had abnormal Transcranial Doppler (TCD) according to STOP - TRIAL (ADAMS). Two of the nine individuals in chronic transfusion treatment had alloimmunization. There was no significant association in the relationship between chronic transfusion treatment and positive IAT-antibody screening ( $p=0.257)$. Alloimmunization rate per 100 RBC units was $0.41 \%$ in this group.

Among the patients who were in the CTT protocol, 2 children were previously alloimmunized and started the transfusion regimen with positive IAT-antibody screening. The offer of phenotyped leuko reduced RBC was unique in two individuals, only in transfusions performed at JFO. The previous exposure to transfusion before positive IAT - antibody screening occurred in five subjects: One of which had been transfused three times, other received 16 units $\mathrm{RBC}$, one child received multiple transfusions with 37 RBC units and two children had transfusion history with report of four transfusions.

\section{Discussion}

In this study, the prevalence of alloantibodies in transfused children with SCD was $11.1 \%$ and $5.3 \%$ in the non-transfused. The prevalence observed in a population of children undergoing chronic transfusion treatment regime was 22.2\%. Chou, et al. and Yazdanbakhsh, et al. correlated alloimmunization and chronic regime transfusion and identified high prevalence rates, such as $32 \%$ from 18 and $45 \%$ [19], even when using phenotyped leukoreduced RBC and performing blood transfusions in unique institutions. In our study the prevalence of alloimmunization among children who received only phenotyped leukoreduced RBC was $25 \%$.

Similar to Chou, et al. [20] our study found a higher prevalence of alloimmunization in multiple transfusions subjects (exposed to RBC transfusion, simple or exchange), especially in those who received more than 10 transfusions (33.3\%). Some individuals become alloimmunized exposed to even small quantities of RBC (37.5\% of alloimmunized received between 1 and 5 transfusions) $[20,21]$. Data presented by Vingert, et al. describes that 50 to $70 \%$ of patients with SCD could never develop alloantibodies despite frequent blood transfusions or chronic transfusion treatment [12].

The average age of identification of irregular antibody was 5.25-years-old. Verduzco and Nathan reported that blood transfusion exposure at an early age could have likely protective role against alloimmunization [22].

The analysis of our data on the type of transfused blood components showed that $25 \%$ of the subjects received phenotyped and leukoreduced RBC. In other health institutions, $50 \%$ of children received transfusion of RBC concentrate on a sporadic basis. These data are very important due to possible correlation between the administration of phenotypically identical blood components and lower alloimmunization rates in SCD populations with multiple transfusions that were performed at Fundação Hemominas [22,23].

The presence of antibodies belonging to Rh system was observed in $9.8 \%$, and two $(22.2 \%)$ patients on chronic transfusion regimen were alloimmunized. Chou, et al. [20] identified the same phenotypes of the Rh system in patients with SCD undergoing hypertransfusion regime with SCD and sporadic transfusions (12\%), suggesting that the implementation of extended genotype research could avoid isoimmunization with reduction of genetic differences between receiver and donor. The Fundação Hemominas is gradually implementing extended genotyping to all donors and the Rh system for patients with SCD in order to improve the compatibility between transfusions and reduce the risk of developing alloantibodies.

Eight patients were observed in chronic transfusion treatment, receiving 416 transfusions (52 units per patient) which give an alloimmunization rate of 0.41/100. Recent studies have found alloimmunization rate of $0.55 / 10024 ; 0.30 / 10020$ and $0.11 / 10023$. The complexity of alloimmunization becomes increasingly a challenge in transfusion therapy in SCD, since beyond the phenotypic differences between donor and recipient there is likely a relationship between the increased formations of antibodies with the increasing number of exposures [24]. Our results did not show any significance between alloimmunization and the amount of transfusions. Therefore, this data should be analyzed with caution, since the number of alloimmunized is quite low (8 individuals) and the $p$ value was only slightly higher than $5 \%(0.085)$.

This study, as well as Fasano, et al. did not show statistical significance related to the number of transfused units, presence of alloantibodies and positive IAT-antibody screening. It was not possible to confirm the risk of alloimmunization in patients undergoing chronic transfusion therapy, despite increased exposure to erythrocyte antigens [5], perhaps because of the small 
population enrolled in this study. There is an ongoing multicenter study searching to establish the association between the number of transfused units and the risk of developing alloimmunization (REDS-III).

Nickel, et al. showed that alloimmunization was more significant in older children with an average age of 13 years and with more exposure to transfusion, without association with sex, age of onset of chronic transfusion treatment and transfusion outside the study institution. The data found in our study were different regarding the average age of alloimmunization (5.25-years-old) and consistent in relation to other variables. Research in Immunohematology area and expanded genotyping may help to prevent and reduce the incidence of alloimmunization in this population [25-31].

Red blood cell transfusion was common in Brazilian patients with SCD, with use driven by CTT. Kelly, et al. described in the Recipient Epidemiology and Donor Evaluation (REDS)-III Brazil cohort, a prevalence of erythrocyte antibody formation in $26.2 \%$ of children, consistent with the data found in this study and in the literature [32].

\section{Conclusions}

Alloimmunization is frequent in patients with $S C D$, attended at JFO, particularly in multiple transfusions. The immunologic sensitization in patients in the chronic transfusion group occurred on dates prior to the beginning of chronic transfusion treatment. Transfusion therapy in the presence of pro-inflammatory events, particularly in SCD, can generate immune response and trigger alloimmunization. There is also a need for genetically similar blood donors, and the miscigenation of the Brazilian population may contribute in the development of alloimunization.

The prevalence of alloimmunization in children in this study was $11.1 \%$ and $50 \%$ of the expressed antibodies belonged to the Rh system, as already presented in the literature. It is important to note that even with the offer of phenotyped and leukoreduced RBC and patients without any transfusion therapy exposure the alloimmunization phenomenon could be detected.

The uses of blood products not phenotyped/leukoreduced and cumulative exposure during emergency treatment are likely contributors to the awareness of children with SCD. Alloimmunization has become frequent with the wide use of chronic transfusion treatment, new studies and methods, such as the implementation of genotyping erythrocyte are mandatory to reduce the identification of gaps gene variants of the Rh system.

The development of alloantibodies is considered a challenge in the treatment of SCD, with restrictive implications for transfusion therapy, considering the early diagnosis, the implementation of transcranial doppler, access to treatment and increased survival in SCD, especially among children with formal indication for chronic transfusion treatment because Stroke risk.

The prescription of phenotyped leukoreduced and genotyped RDC throughout the health team involved in the treatment and follow-up of children with sickle cell disease should be a strategy to try to reduce the development of alloimmunization related to transfusion therapy and the immune complications determined by the presence of alloantibodies.

\section{Acknowledgements}

The authors acknowledge the support of FAPEMIG/ PPSUS and Fundação Hemominas. National Intitutes of Health (NIH) REDSIII SCD Study.

\section{Conflicts of Interest}

The authors declare no conflicts of interest.

\section{References}

1. Ataga KI, Key NS (2007) Hypercoagulability in sickle cell disease: New approaches to an old problem. Hematology Am Soc Hematol Educ Program 2007: 91-96.

2. Cançado RD, Jesus JA (2007) A doença falciforme no Brasil. Ver BrasHematolHemoter 29: 203-206.

3. BRASIL-DF (2012) Ministério da Saúde. Doença falciforme: Condutas básicas para tratamento. Ministério da Saúde, Secretaria de Atenção à Saúde, Departamento de Atenção Especializada. Brasília: Ministério da Saúde, 2012. 64 p.: il. ISBN 978-85-334-1932-2).

4. Fernandes $A P$, Januário JN, Cangussu $C B$, Macedo DL, Viana MB (2010) Mortality of children with sickle cell disease: A population study. J Pediat 86: 279-284.

5. Fasano RM, Booth GS, Miles M, Liping D, Koyama T, Meier ER, et al. (2015) Red blood cell alloimmunization is influenced by recipient inflammatory state at time of transfusion in patients with sickle cell disease. Br J Haematol 168: 291-300.

6. Wahl S, Quirolo KC (2009) Current issues in blood transfusion for sickle cell disease. Curr Opin Pediatr 21: 15-21.

7. Schonewille H, Van De Watering LMG, Loomans DSE, Brand A (2006) Red blood cell alloantibodies after transfusion: factors influencing incidence and specificity. Transfusion 46: 250-256.

8. Pinto PC, Braga JA, Santos AM (2011) Risk factors for alloimmunization in patients with sickle cell anemia. Rev Assoc Med Bras 57: 654-659.

9. Tatari-Calderone Z, Luban NLC, Vukmanovic S (2014) Genetics of transfusion recipient alloimmunization: Can clues from susceptibility to autoimmunity pave the way? Transfus Med Hemother 41: 436-445.

10. Pereira A (2018) Red blood cell alloimmunization: Still a major complication of blood transfusion. $\mathrm{Br} \mathrm{J}$ Haematol 181: $575-576$.

11. Karafin MS, Westlake M, Hauser RG, Christopher A Tormey, Philip J Norris, et al. (2018) Risk factors for red blood cell alloimmunization in the recipient epidemiology and donor evaluation sStudy (REDS-III) database. $\mathrm{Br} \mathrm{J}$ Haematol 181: 672-681.

12. Aygun B, Padmanabhan S, Paley C, Chandrasekaran V 
(2002) Clinical significance of RBC alloantibodies and autoantibodies in sickle cell patients who received transfusions. Transfusion 42: 37-43.

13. Castro O, Sandler Sg, Houston-Yu P, Rana S (2002) Predicting the effect of transfusing only phenotype-matched RBCs to patients with sickle cell disease: Theoretical and practical implications. Transfusion 42: 684-690.

14. Vingert B, Tamagne M, Habibi A, Pakdaman S, Ripa J, et al. (2015) Phenotypic differences of CD4 (+) T cells in response to red blood cell immunization in transfused sickle cell disease patients. Eur J Immunol 45: 1868-1879.

15. Murao M, Viana MB (2005) Risk factors for alloimmunization by patients with sickle cell disease. Braz J Med Biol Res 38: 675-682.

16. Vichinsky Ep, Earles A, Johnson Ra, Hoag Ms, Williams A, et al. (1990) Alloimmunization in sickle cell anemia and transfusion of racially unmatched blood. N Engl J Med 322 1617-1621.

17. Vichinsky EP (2012) The prevention and management of alloimmunization in sickle cell disease: The benefit of extended phenotypic matching of red blood cells. Immunohematology 28: 20-23.

18. BRASIL. Ministério da Saúde. Portaria GM 158, (2016) Normas técnicas para coleta, processamento e transfusão de sangue, componentes e hemoderivados. Diário Oficial (República Federativa do Brasil), Brasília.

19. Yazdanbakhsh K, Ware RE, Noizat-Pirenne F (2012) Red blood cell alloimmunization in sickle cell disease: Pathophysiology, risk factors, and transfusion management. Blood 120: 528-537.

20. Chou ST, Jackson T, Vege S, Smith-Whitley K, Friedman DF, et al. (2013) High prevalence of red blood cell alloimmunization in sickle cell disease despite transfusion from Rh-matched minority donors. Blood 122: 1062-1071.

21. Nickel RS, Osunkwo I, Garrett A, Robertson J, Archer DR, et al. (2015) Immune parameter analysis of children with sickle cell disease on hydroxycarbamide or chronic transfusion therapy. Br J Haematol 169: 574-583.

22. Verduzco LA, Nathan DG (2009) Sickle cell disease and stroke. Blood 114: 5117-5125.
23. Miller ST, Kim HY, Weiner DL, Wager CG, Gallagher D, et al. (2013) Red blood cell alloimmunization in sickle cell disease: Prevalence in 2010. Transfusion 53: 704-709.

24. Vichinsky EP, Luban NL, Wright E, Olivieri N, Driscoll C, et al. (2001) Prospective RBC phenotype matching in a stroke-prevention trial in sickle cell anemia: A multicenter transfusion trial. Transfusion 41: 1086-1092.

25. Wahl SK, Garcia A, Hagar W, Gildengorin G, Quirolo K, et al. (2012) Lower alloimmunization rates in pediatric sickle cell patients on chronic erythrocytapheresis compared to chronic simple transfusions. Transfusion 52: 2671-2676.

26. Godfrey GJ, Lockwood W, Kong M, Bertolone S, Raj A (2010) Antibody development in pediatric sickle cell patients undergoing erythrocytapheresis. Pediatr Blood Cancer 55: 1134-1137.

27. Nickel RS, Horan JT, Fasano RM, Meyer E, Josephson CD, et al. (2015) Immunophenotypic parameters and RBC alloimmunization in children with sickle cell disease on chronic transfusion. Am J Hematol 90: 1135-1141.

28. Fichou Y, Mariez M, Le Maréchal C, Férec C (2016) The experience of extended blood group genotyping by next generation sequencing (NGS): Investigation of patients with sickle-cell disease. Vox Sang 111: 418-424.

29. Yazdanbakhsh K (2016) Immunoregulatory networks in sickle cell alloimmunization. Hematology Am Soc Hematol Educ Program 2016: 457-461.

30. Fasano RM, Chou ST (2016) Red blood cell antigen genotyping for sickle cell disease, thalassemia and other transfusion complications. Transfuse Med 30: 197-201.

31. Chou ST, Westhoff CM (2017) Application of genomics for transfusion therapy in sickle cell anemia. Blood Cell Mol Dis 67: $148-154$

32. Kelly S, Belisário AR, Werneck Rodrigues DO, Thelma T Gonçalez, Paula Loureiro, et al. (2020) Blood utilization and characteristics of patients treated with chronic transfusion therapy in a large cohort of Brazilian patients with sickle cell disease. Transfusion 60: 1713-1722. 